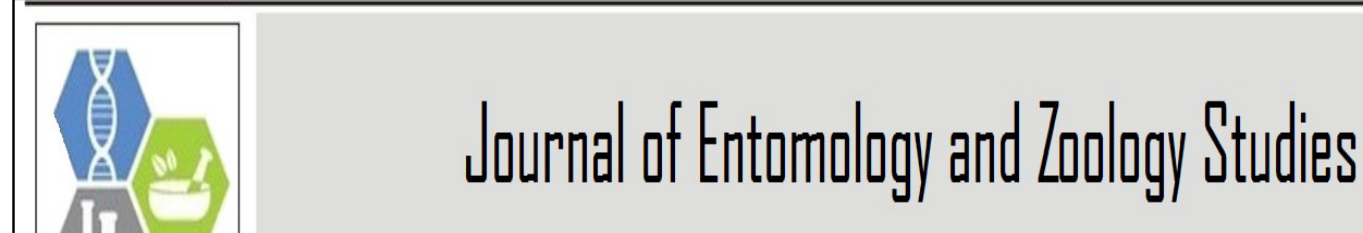

Available online at www.entomoljournal.com

\section{E-ISSN: 2320-7078 P-ISSN: 2349-6800 JEZS 2016; 4(4): 389-391 \\ (C) 2016 JEZS \\ Received: 13-05-2016 \\ Accepted: 14-06-2016}

Mark Ian Cooper

Department of Biological

Sciences, Private Bag X3,

University of Cape Town,

Rondebosch 7701, South Africa;

Electron Microscope Unit,

University of Cape Town.

Correspondence

Mark Ian Cooper

Department of Biological

Sciences, Private Bag X3,

University of Cape Town,

Rondebosch 7701, South Africa;

Electron Microscope Unit,

University of Cape Town.

\title{
Confirmation of four species of Centrobolus Cook (Spirobolida: Trigoniulidae) based on gonopod ultrastructure
}

\section{Mark Ian Cooper}

\section{Abstract}

Specific status of Centrobolus inscriptus, C. annulatus, C. fulgidus and C. ruber was confirmed using gonopod ultrastructure. Informative regions were identified and labelled on their gonopods (phallopods and coleopods).

Keywords: diplopod, coleopod, gonopod, millipede, phallopod, Centrobolus

\section{Introduction}

The revision of the genus Centrobolus (Cook, 1897) was considered a desideratum ${ }^{[6]}$ As many as 39 species are recognized in the genus ${ }^{[5]}$ Although a complete revision of the genus is still a desideratum, here I present gonopod structure of four species. My species have disparate copulation durations as well as the characters presented herein ${ }^{[3-4]}$. This makes them probably reproductively isolated species. No known cases of hybridisation are known for any of the taxa. The tentative null hypothesis is that the gonopods can be used to describe valid millipede species.

\section{Materials and Methods}

Four species of Centrobolus were identified a priori based on morphology and confirmed using Scanning Electron Microscopy (SEM) of gonopod structure (1995-1998). The gonopods were dissected from dead males of these four species and prepared for SEM. Specimens were fixed, first in $2.5 \%$ glutaraldehyde ( $\mathrm{pH} 7.4$ phosphate-buffered saline) at $4{ }^{\circ} \mathrm{C}$ for 24 hours, then in osmium tetroxide $(2 \%)$. Dehydration through a graded alcohol series $(50 \%, 60 \%, 70 \%$, $80 \%, 90 \%$ to $100 \%$ ethanol) and critical point drying followed. Specimens were mounted on stubs and sputter-coated with gold palladium. Gonopods were viewed under a Cambridge S200 SEM. SEM micrographs were examined and the individual components of the gonopods were identified according to the available species descriptions. Two sets of linear measurements were made from the SEM micrographs: (1) prominence of the stemite. This has been estimated before as a ratio of how far it extends from the basal region up to the top of the coleopod, and (2) length of the spines present on the distal knob were estimated from measurements taken directly from SEM images. The collection of SEM micrographs for each species are particularly informative when comparisons are made between congruent views.

\section{Results and Discussion}

Informative regions were identified and labelled on the relaxed gonopods of the four species:

\subsection{Centrobolus annulatus (Attems, 1934)}

Locality: Twin Streams Farm, Mtunzini. Coleopods: The basal joint (b) is angular on the inner side. The distal joint (d) bears a lappet near the terminal thickening, the latter beset with little conical points that will be termed the "spines". Phallopods: The distal lamellae (dl), more appropriately termed the lappet for obvious and also potentially functional reasons, are broadly rounded and low, not reaching the margin. (cf. Attems 1934, fig. 50).

\subsection{Centrobolus inscriptus (Attems, 1928)}

Locality: Twin Streams Farm, Mtunzini. Coleopods: The sternite (v) is triangular and prominent up to the middle of the gonopod (Table 1). The basal joint (b) is broad and rounded at the tip while the second joint (d) is somewhat narrow with two lateral lobes. The summit (k) of the telopodite is covered with little knobs and spines seated in pits. 
Phallopods are not visible from the plate: the broad tibial process (ti) that projects a little ${ }^{[8]}$. The lappet differs from the previous species in that it extends beyond the margin ${ }^{[1]}$.

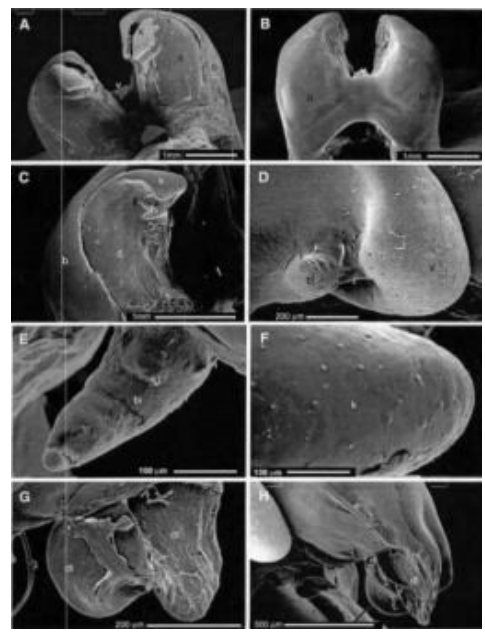

Plate 1: Centrobolus annulatus gonopods. A. Aboral view of the coleopod showing its distal (d) component carrying the knob (k) and the "bill" (bi) and its basal (b) component; B. Oral view of the: coleopods with the stemite (v) positioned medially, C- 0 . Lateral views of the right distal telopodite lobe, E. Lower distal telopodite lobe or bill, F. Surface of the distal telopodite lobe knob, G-H. Distal lamellae (dl) of the phallopod with a prominent chitinous ridge (e).

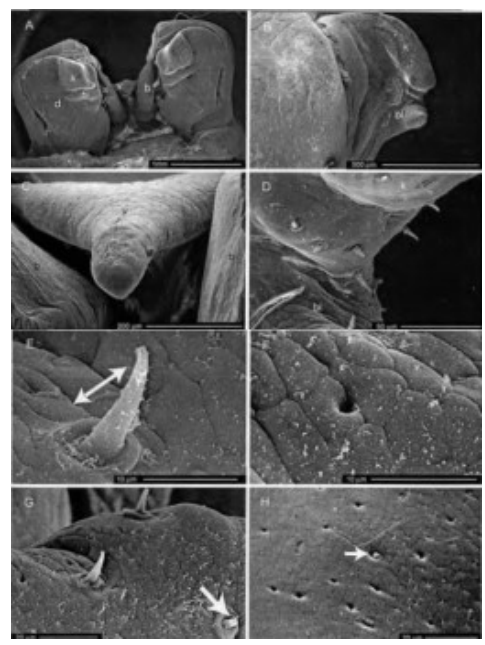

Plate 2: Centrobolus inscriptus gonopods. A. Aboral view of the coleopods; B. Lateral views of the right distal telopodite lobe bearing the knob (k) and bill (bi); C. Aboral view of the sternite (v) emerging medially between the basal joints (b) of the coleopod; D. Topology of the distal telopodite lobe; E. The speculated sensory spine with the (arrow) indicating its movement against the basal cell; F. A surface pit; G. Closer examination revealed damage to some of the spines (arrow) possibly inflicted in copula; H. Surface pit with a trapped particle (arrow).

\subsection{Centrobolus fulgidus (Lawrence, 1967)}

Locality: Richard's Bay. Coleopods: The distal joint (d) has an elongated lower lobe produced laterally plus three ridges medially. The distal region of the coleopods are not as broad in the other three. The species descriptions given here are congruent with those originally described and accompanied by line drawings made through light microscopes and hand lenses ${ }^{[1,2,5-9]}$. The position of the phallopods is such that they are seated behind, and protected by the coleopods. The static examination of the gonopod ultrastructures did not reveal the phallopods but the entire structural complexity of the phallopod is revealed from an examination of their mechanics in copula ${ }^{[3]}$.

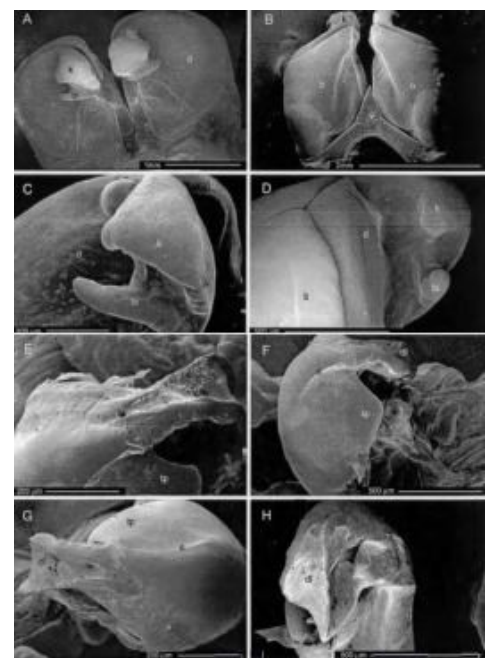

Plate 3: Centrobolus fulgidus gonopods. A-B. Aboral and oral views of the coleopods showing the distal (d) region with a lobe bearing the knob (k) and bill (bi), the basal (b) component and the sternite (v); C- D. Aboral and lateral views of the distal telopodite lobe showing the slender species-specific bill and knob; E. The recurved distal lamella (dl) of the phallopod with a triangular gap aside the tibial process (tp); F. The tibial process is flanged; G. The chitinous ridge is extensive; H. The "scoop" exemplifies an elaboration of an already complex structure.

\subsection{Centrobolus ruber (Attems, 1928)}

Locality: Anele, Port Shepstone. Coleopods: The basal joint (b) has a straight internal margin and oblique terminal margin, connected by a wide arch with the outer margin. The tip of the second joint has a thick black knob, bearing a little lobe ${ }^{[5]}$ (Table 1). The lappet of the distal joint (d) is close to the terminal thickening. The sternite is pointed and relatively short (Table 1) ${ }^{[5]}$. Phallopods: The tibial process (ti) is broad, projecting but little, with a smooth margin; between the tibial process and the tip is a pointed lobe, the distal lappet (dl) is longer than wide ${ }^{[5-6]}$.

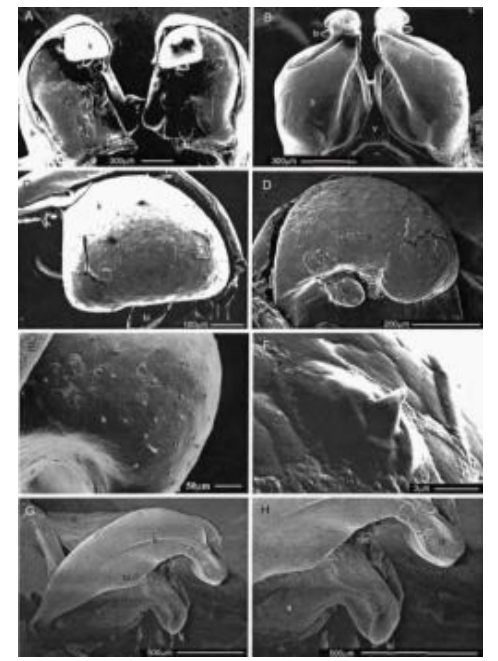

Plate 4: Centrobolus ruber gonopods. A-B. Aboral and oral views of the coleopods showing the slender distal telopodite region (d) with hidden bill (hi) and rounded knob (k) visible above the basal region in oral view; C-D. Aboral and medio-lateral views of the distal lobe focussing on its reduced components; E. Miniature spines associated with the knob; F. A single spine; G. The tapered phallopod and reduced tibial process (tp); H. The distal lamella has no scoop. 
Table 1: Male genital measurements of four Centrobolus millipedes that were estimated from scanning electron micrographs.

\begin{tabular}{|c|c|c|c|}
\hline Species & Sternite prominence (\%) & Spine Length & $\mathbf{n}$ \\
\hline C. annulatus & 30 & 5 & 21 \\
\hline C. inscriptus & 50 & 10 & 10 \\
\hline C. fulgidus & 35 & - & - \\
\hline C. ruber & 25 & 2.5 & 23 \\
\hline
\end{tabular}

Sternite prominence ( $\%$ of total gonopod height) and spine length ( $\mu \mathrm{um})$ were estimated from single specimens and the number of spines present was counted (n)

\section{References}

1. Attems C. The Myriapoda of South Africa. Annals of the South African Museum. 1928; 26:1402.

2. Attems C. The Myriapoda of Natal and Zululand. Annals of the Natal Museum. 1934; 7:459522.

3. Cooper MI. Gonopod mechanics in Centrobolus Cook (Spiroboloidea: Trigoniulidae). International Journal of Entomology Research. 2016; 1(1):37-38.

4. Cooper MI, Telford SR. Copulatory Sequences and Sexual Struggles in Millipedes. Journal of Insect Behaviour. 2000; 13:217-230.

5. Hamer ML. Checklist of Southern African millipedes. Annals of the Natal Museum 1998; 39:11-82.

6. Hoffman RL. A note on the status of the name Centrobolus Cook, 1897 Spirobolida, Pachybolidae. Myriapodologica. 2001; 7:49-52.

7. Jeekel CAW. Milliped Miscellany- Part III. Beaufortia. 1956; 5:73-99.

8. Lawrence RF. The Spiroboloidea (Diplopoda) of the eastern half of southern Africa. Annals of the Natal Museum. 1967; 18: 607-646.

9. Schubart O. Diplopoda III. Psephalognatha, Opisthospermomorpha, Colobognatha. South African Animal Life. 1966; 12:7-227. 